\title{
On the Construction of the Quality Assurance System for the Teaching of Advertising Majors in Colleges and Universities
}

\author{
Jian $\mathrm{Xu}^{1}$ \\ ${ }^{1}$ Qujing normal university, yunnan qujing city kirin sanjiang avenue, 655011 \\ 14027400@qq.com
}

Keywords: Advertising science; Teaching quality; Guarantee system

\begin{abstract}
As more and more enterprises realize the importance of advertising to the information dissemination of enterprises, the demand for advertising talents is increasing. Many colleges and universities offer advertising major. However, some advertising graduates in the employment process, such as theoretical foundation is not solid, practical ability is not strong and so on. Therefore, in the professional construction, teaching quality construction is the top priority, especially the construction of teaching quality assurance system. Taking the advertising specialty of Qujing Normal University as an example, this paper explores the construction of the teaching quality assurance system of the major, and puts forward the corresponding suggestions and suggestions.

With the promotion of the importance of marketing in business management, advertising has gradually become the most effective means of communication in the promotion strategy of enterprises. In order to better meet the needs of advertising talents, many colleges and universities have opened advertising major to train highly qualified and highly skilled advertising professionals. The construction of advertising science is a systematic project with complex elements and many factors. Teaching quality is the most essential factor for a professional development. The quality of teaching directly affects the construction and development of majors, the improvement of students' abilities and employment. In the construction of the teaching quality of advertising majors, there are some problems, such as unclear construction goals, unreasonable construction of teachers and teaching conditions.

In conjunction with the needs of local economic and social development, Qujing Normal University opened a undergraduate major in advertising in 2004. Since, in order to cultivate senior advertising professionals, to better serve the local social services, we strengthen the construction of teaching quality, in specialty construction, to ensure the advertising professional teaching conditions, improve the quality of teaching professional, constructing teaching quality guarantee system, and achieved good results.
\end{abstract}

\section{Strengthening the Construction of the Leadership Team and Strengthening the Overall Joint Force}

The leadership team is the maker and executor of the strategy in the professional construction, and its role is throughout the whole process of professional construction. A good leadership team can promote the learning and thinking of the whole team, and also strengthen and lead the innovation and change of the professional construction. In practice, we need according to the professional construction of advertising, the establishment of professional responsibility to set up the professor as the representative of professional construction team, responsible for the advertising specialty construction, which is mainly responsible for the selection from the responsibility of teachers with professional requirements and conditions of teachers, which led the team responsible for the professional construction.

Under the leadership of the leadership team, all teachers should be required to build up the overall concept and cooperation consciousness. In the management, we should vigorously promote and strengthen the mutual exchange and cooperation between departments and departments so as to realize the common development and utilization of educational resources. If each semester is 
scheduled for teaching tasks, interdisciplinary courses and interpenetration of Arts and sciences will invite relevant professional teachers to undertake teaching tasks, so as to ensure the completion of teaching tasks. The leadership team in the long term planning, highlighting the characteristics and efficiency principle, from the human, financial and material resources fully give advertising professional tilt, equipped with professional team of teachers, provide rich teaching facilities, increase investment, to provide good teaching conditions for the advertising specialty construction, enhance the overall efforts to ensure the professional construction and teaching work.

\section{Strengthening the Construction of Teachers and Improving the Quality of Teachers}

Advertising is a comprehensive and cross discipline, actively cultivating advertising professional teachers is the key to strengthen the professional construction, which requires the use of "introduction, training, diversion and so on many kinds of ways in specialty construction, pay attention to the construction of teachers, enhance the team level, structure, specialization and strength, build a business in accordance with the professional characteristics, excellent quality, reasonable structure, stable staff team of teachers, is a key premise for advertising professional construction. One is to make a reasonable plan for the construction of teachers. According to the professional training plan and requirements, the institute makes a detailed plan for the construction of the teaching staff, and defines the direction, goals and annual implementation plan of the advertising faculty construction in a certain period, so as to provide a basis for the construction of the teaching staff. The two is to pay attention to the introduction of high level advertising professionals. In the mechanism of introducing talents, high-level talents and actively and carefully introduce advertising professional, full-time teachers to form a highly educated and skilled advertising as the backbone of the teachers, and in the practice of educational structure, title structure, age structure of scientific and reasonable teaching echelon form gradually. Three is to hire outside experts to strengthen guidance. Before and after the college hired experts in many other universities in Yunnan to guide the construction of professional advertising, no regular and enterprises to strengthen exchanges, and jointly with the experts and enterprise managers to carry out the teaching level of regular professional evaluation and research, in order to guarantee the high quality of advertising specialty construction. The four is to pay attention to the selection of teachers in the course of professional courses. The main course of the advertising major must be a full-time teacher with a professional title above the lecturer. The five is to strengthen the training and advertising practice. In order to train teachers' practical ability, increase the combination of teaching and practice, encourage teachers to regularly participate in professional content training, cooperate with enterprises, participate in professional qualification tests, expand knowledge and improve teaching level of teachers. The six is to carry out teaching research regularly. Teachers should be encouraged to conduct regular teaching research, carry out targeted discussions, analysis and communication, summarize teaching experience and improve teachers' professional teaching quality. Seven is the establishment of teacher evaluation mechanism, the implementation of teaching quality monitoring, to ensure that teachers play the most important role in the teaching.

\section{Improving the Condition of Running a School and Strengthening the Strength of Running a School}

In 2004, the Ministry of Education issued the basic criteria for running schools for ordinary colleges and universities (Trial). The fundamental task of uni versities is to train high-quality professionals. The conditions for running colleges and universities are the important guarantee for achieving this fundamental task, and also the premise and foundation for education and teaching. School conditions such as "teaching and administrative buildings, libraries, laboratories, campus network, sports venues and so on are necessary conditions meet the training needs, not only have these conditions, but also to good use, to improve the training quality of the maximum play an active role in." [1]The construction of school and college attaches great importance to advertising professional school conditions, and actively apply the basic construction to speed up the real teaching, 2005 
established advertising professional studio, established in 2007 ad studio, the establishment of the school of high performance computer room, photography laboratory, non laboratory, to meet the teaching and Practice of advertising and related professional needs. Actively carry out the declaration and purchase of equipment and instruments. From the beginning of 2005, started to purchase large plotters, laminator, cameras, photographic equipment and other advanced equipment and instruments, auxiliary teaching. Increase the book information input, the school library a lot of advertising books and materials to the professional teachers and students open, not only that, our hospital has established a professional library, providing resources to teachers, and to realize the sharing of resources, so as to strengthen the advertising professional strength of the school, the link to ensure the smooth teaching for.

\section{Strengthening Project Support and Promoting Professional Construction}

Teaching and scientific research are the two core functions of colleges and universities, and it is an important content that affects the development of colleges and universities. All the time, there has been a debate about "heavy teaching, light scientific research" and "light teaching and heavy scientific research". In fact, teaching and research in higher education is not contradictory, can not replace each other, teaching and research is an indivisible whole, high quality teaching can effectively promote the development of scientific research, and the high level of scientific research to promote teaching reform, the two are complementary and jointly promote the. With the deepening of teaching reform in Colleges and universities, scientific research has gradually become an important evaluation standard for professional construction and teacher assessment. In the process of construction of advertising specialty in our college, we apply for the special construction funds actively according to the special funds for Discipline and specialty construction, so as to ensure that the funds are in place. The organization of teachers and professional construction research, successively to various universities and some enterprises in Yunnan to carry out research, strengthen exchanges and cooperation; actively encourage teachers as a team of project application, project teaching reform, many advertising courses become high-quality school curriculum; curriculum construction actively promote, so far, advertising has been established in the "advertising photography", "marketing and investigation" courses such as the representative of the network course construction. At the same time, the professional data room and teaching and research room are also building up to promote the teaching of advertising major.

\section{Building a Curriculum System to Improve the Quality of Talent Training}

The construction of curriculum system is "based on the needs of the society, the needs of students and the needs of discipline development. Based on the macro level, it aims to improve the quality of education for the purpose of national education and school running. "[2] The construction of curriculum system is the core content of teaching reform and professional construction in Colleges and universities. Therefore, we strive to optimize the advertising curriculum structure, strengthen the professional basic courses and main course teaching, and open courses, expand quality courses and set up second classes to achieve cross disciplinary penetration and improve the comprehensive quality of students. Teachers require teachers to formulate syllabus and examination syllabus, and continue to discuss and amend them so that they can better guide the teaching. Usually, attention should be paid to the routine construction and teaching of professional courses. Teachers should perfect curriculum construction in practice, such as compiling syllabus, building examination questions database, building online courses, integrating learning resources, and using multimedia, so as to achieve standardization and modernization of curriculum construction. At the same time, we have made great efforts to set up special courses in advertising specialty to form a special curriculum system with distinctive features of advertising. The college also attaches great importance to the reform and innovation of the teaching contents and methods of the specialty of advertising. 


\section{Increase the Construction of Practical Teaching and Improve the Professional Skills}

Advertising has the characteristics of comprehensive application, etc., in order to improve the teaching quality of advertisement major in Colleges and universities and students' professional skills training, senior advertising professionals meet the needs of society, we must strengthen the combination of theoretical teaching and practical teaching, so the construction of practical teaching system of professional advertising is becoming more and more important. The first is to strengthen the construction and update of the advertising laboratory, and provide a good teaching and practical environment for teachers and students. The two is to strengthen the training of professional skills in advertising, and combine the practical construction of the curriculum with the professional comprehensive practice teaching. According to the construction of teaching practice in different courses, teachers must set up curriculum practice contents according to the requirements of teaching and training programs, and form a comprehensive practice teaching based on professional probation, professional practice, graduation thesis (planning and Design). The three is to strengthen the work of graduation thesis (planning and Design). Require teachers and students pay attention to the graduation thesis work in advertising within the framework, to provide students with the planning, design, three kinds of forms, you can choose one form to complete the link work; will arrange professional teachers for professional guidance to students, improve their quality, and finally to the graduation exhibition form to test students the results of. The four is to establish the training base actively and strengthen the cooperation between school and enterprise. According to the requirements of advertising training program, we need to establish certain training bases, such as advertising companies, schools and enterprises, to provide more training opportunities for students. At the same time, we should strengthen cooperation with enterprises, improve students' professional skills and practical ability, and ultimately improve students' comprehensive ability.

\section{Reference}

[1] H.J. Liu and G.D. Lu: Improving the Conditions of Local Colleges and Universities to Improve the Quality of Personnel Training,(2008) No.1, p.61-63. (In Chinese)

[2] B.Y. Guo: Comparison and Analysis of the Construction of Curriculum Group and the Construction of Curriculum System,(2005) No.4, p.114-116. (In Chinese) 